\title{
Biological hydrogen production from synthetic wastewater by an anaerobic migrating blanket reactor: Artificial neural network (ANN) modeling
}

\author{
Mohammad Ghasemian $^{1,2}{ }^{\mathbb{D}}$, Ensiyeh Taheri ${ }^{1,2}{ }^{\mathbb{D}}$, Ali Fatehizadeh $^{1,2}{ }^{\mathbb{D}}$, Mohammad Mehdi Amin $^{1,2^{*} \mathbb{D}}$ \\ ${ }^{1}$ Environment Research Center, Research Institute for Primordial Prevention of Non-communicable Disease, Isfahan University of \\ Medical Sciences, Isfahan, Iran \\ ${ }^{2}$ Department of Environmental Health Engineering, School of Health, Isfahan University of Medical Sciences, Isfahan, Iran
}

\begin{abstract}
Background: This study aimed to evaluate an anaerobic migrating blanket reactor (AMBR) for biological hydrogen production, and also to investigate its capability to treat synthetic wastewater.

Methods: A five-compartment AMBR (9 L effective volume) was made by Plexiglas and seeded with thermal pretreated anaerobic sludge at $100^{\circ} \mathrm{C}$ for 30 minutes. The AMBR was operated at mesophilic temperature $\left(37 \pm 1^{\circ} \mathrm{C}\right)$ with continuous fed of synthetic wastewater at five organic loading rates (OLRs) of 0.5 to $8 \mathrm{~g} \mathrm{COD/L.d.}$

Results: It was revealed that as the OLR increased from 0.5 to $8 \mathrm{~g} \mathrm{COD/L.d,} \mathrm{the} \mathrm{hydrogen} \mathrm{production}$ and also volumetric hydrogen production rate (VHPR) improved. Increasing the OLR over this range, led to a decrease in the average hydrogen yield from $1.58 \pm 0.34$ to $0.97 \pm 0.45 \mathrm{~mol} \mathrm{H}_{2} / \mathrm{mol}$ glucose. The concentration of both volatile fatty acids (VFAs) and solvents kept increasing with OLR. During the AMBR operation, the dominant soluble end products (SEPs) were acetic and butyric acids in all of the OLRs studied.

Conclusion: Based on the results, the hydrogen yield was related to the acetate/butyrate fermentation. The artificial neural network (ANN) model was well-fitted to the experimental obtained data from the AMBR, and was able to simulate the chemical oxygen demand (COD) removal and hydrogen production.

Keywords: AMB reactor, Fatty acids, Fermentation, Hydrogen, Wastewater treatment

Citation: Ghasemian M, Taheri E, Fatehizadeh A, Amin MM. Biological hydrogen production from synthetic wastewater by an anaerobic migrating blanket reactor: artificial neural network (ANN) modeling. Environmental Health Engineering and Management Journal 2019; 6(4): 269-276. doi: 10.15171/EHEM.2019.30.
\end{abstract}

Article History:

Received: 6 August 2019

Accepted: 17 October 2019

ePublished: 21 November 2019

\section{Introduction}

Hydrogen $\left(\mathrm{H}_{2}\right)$ as an environmentally friendly gas is an energy carrier that could play a significant role in the reduction of greenhouse gases $(1,2)$. Due to water production during combustion process, $\mathrm{H}_{2}$ is considered as a clean fuel. Hydrogen is regarded as an ideal energy with a high energy yield of $122 \mathrm{~kJ} / \mathrm{g}$, which is 2.75 folds greater than that of hydrocarbon fuels (3).

In comparison with conventional anaerobic process (fermentative methane production), due to some inconsistency and drawbacks, the $\mathrm{H}_{2}$ production processes by dark fermentation are less well developed than the methane $\left(\mathrm{CH}_{4}\right)$ production. During anaerobic digestion of organic wastes, such as solid waste and wastewater, $\mathrm{CH}_{4}$ is produced and its production processes have been well established commercially. Hydrogen is a more valuable energy carrier and chemical feedstock compared with $\mathrm{CH}_{4}(4,5)$.

Apart from the difficulties in the stabilization of process, the low yield of $\mathrm{H}_{2}$ on sugars was reported. Based on the glucose stoichiometry, the oxidation of $1 \mathrm{~mol}$ of glucose can produce $12 \mathrm{~mol} \mathrm{H}_{2}$. In dark fermentation process, the maximum yield of $\mathrm{H}_{2}$ is $4 \mathrm{~mol}$ per mol of glucose, which is only $33 \%$ of the theoretically stoichiometric and linked to microbial metabolism. In the $\mathrm{H}_{2}$ production by dark fermentation process at present, during carbon conversion to various organic acids and alcohols, $\mathrm{H}_{2}$ is not produced from the simple oxidation reactions of glucose to $\mathrm{CO}_{2}$ and water $(4,6)$.

The maximum $\mathrm{H}_{2}$ production via dark fermentation is 
related to the operational $\mathrm{pH}$, substrate concentration (various carbohydrates), influent nutrients ( $\mathrm{N}$ and $\mathrm{P}$ ), hydraulic retention time (HRT), partial pressure of $\mathrm{H}_{2}$, stirring rate, sludge pretreatment methods (e.g., thermal or acid or alkaline pretreatment), and the absence or activity inhibition of hydrogenotrophic methanogens (710). Previous studies on the $\mathrm{H}_{2}$ bioreactors shows that the important design parameter is organic loading rate (OLR) (11).

Due to metabolites (volatile fatty acids [VFAs] and solvents) accumulation during fermentation, the solution $\mathrm{pH}$ drops and buffering capacity (BC) reduces, and as a result, leads to the inhibition of biological $\mathrm{H}_{2}$ production (12). Furthermore, the acid-base condition of treatment system was expressed with VFAs concentration and solution $\mathrm{pH}$. In addition, with increasing the $\mathrm{BC}$, the redox condition of treatment system can be controlled. Furthermore, with increasing BC, the treatment system can be operated in a stable solution $\mathrm{pH}$. The buffer supplementation at various solution $\mathrm{pHs}$ increased the $\mathrm{H}_{2}$ production time by maintaining the optimum solution $\mathrm{pH}$. In order to increase the treatment system $\mathrm{BC}, \mathrm{CO}_{2}$ was introduced to the bioreactor and lead to an increase in the $\mathrm{H}_{2}$ production (13). The pretreatment of biocatalyst and also acidophilic conditions will facilitate the effective biological $\mathrm{H}_{2}$ production during various wastewater treatment processes (14).

Different batch and continuous technologies, such as anaerobic sequencing batch reactor (ASBR) (15-17), upflow anaerobic packed bed reactor, anaerobic digester sludge, and membrane bioreactor have been used for the biological $\mathrm{H}_{2}$ production (15). The anaerobic migrating blanket reactor (AMBR) is a high rate anaerobic treatment system that is operated independent of an upflow hydraulic pattern for mixing. The required contact between the substrate and biomass, was supplied using mechanical mixing. The biomass migration occurs in the horizontal flow in this system. To avoid solid-liquid phase separation and also, the sludge agglomeration in the bottom part of the reactor, the periodical flow reversal pattern is used in this mechanism. This system is a continuous flow by a short HRT, which is designed simply and does not need effluent recycling and gas-liquid separation system $(18,19)$.

The artificial neural network (ANN) is a good tool working according to human nerve systems and brain that is broadly used to examine relationships in complex nonlinear data due to the ANN ability to data classification and learning. During the last decade, the ANN models have been used for the environmental engineering fields, such as biological treatment of wastewater, membrane filtration, pollution adsorption, and electrodialysis of saline water (20-23).

The ANNs always consist of three layers including (i) input, (ii) hidden, and (iii) output layers. The outputs of a neuron are calculated using Eq. (1):
$o=f\left(\sum_{J=0}^{n} \omega_{i j} \times x_{j}\right)$

where $n$ is the input number, $x_{j}$ is the $j^{\text {th }}$ input to the neuron, $\omega_{j}$ is the $j^{\text {th }}$ synaptic weight, and $f$ is a non-linear function.

For converting output data between -1 and +1 , the hyperbolic tangent formula was applied as Eq. (2):

$\tanh (x)=\frac{2}{1+e^{-2 x}}-1$

During training process of input and output data set, the network weights are adjusted to achieve the similar outputs as seen in the training data set. For this purpose, the data were divided into two subsets for training model and validation purposes.

The Pearson correlation coefficient $\left(r^{2}\right)$ and mean standard error (MSE) were computed to evaluate the performance of the developed models according to the following formulas (24).

$$
\begin{aligned}
& r^{2}=1-\frac{\sum_{i=1}^{N}\left(y_{\text {pre }, i}-y_{\text {exp }, i}\right)^{2}}{\sum_{i=1}^{N}\left(y_{\text {pre }, i}-y_{\text {ave }}\right)^{2}} \\
& M S E=\frac{1}{N} \sum_{i=1}^{N}\left(\left|y_{\text {pre }, i}-y_{\text {exp }, i}\right|\right)^{2}
\end{aligned}
$$

In order to avoid numerical overflows related to very large or small weights, all of the data were converted to normalized values using Eq. (5):

$x_{n o r m}=0.8 \times\left(\frac{x_{i}-x_{\min }}{x_{\text {max }}-x_{\min }}\right)+0.1$

Due to lack of related studies, the performance and efficiency of AMBR for biological hydrogen production and wastewater treatment in different initial OLR values were evaluated in the present study. In addition, the ANN model was developed to predict the performance of the AMBR for wastewater treatment and hydrogen production.

\section{Materials and Methods}

AMBR set up and operation

A 9-L continuous AMBR was made by Plexiglas with dimensions of $9 \times 10 \times 20 \mathrm{~cm}(\mathrm{~L} \times \mathrm{W} \times \mathrm{H})$. The AMBR contained five compartments with the same size and total volume of $10 \mathrm{~L}$ and a $1 \mathrm{~L}$ headspace for the collection of biogas and foam. The flow regimes in the compartments were constituted with an up-flow and down-flow zone. The schematic diagram of the AMBR is shown in Figure 1. The gas collection systems consisted of gas sampling ports, gas pipes, and wet gasmeter. For biological solids trapping and also water level control, the last compartment was attached to a sedimentation tank (1.5 L volume). 


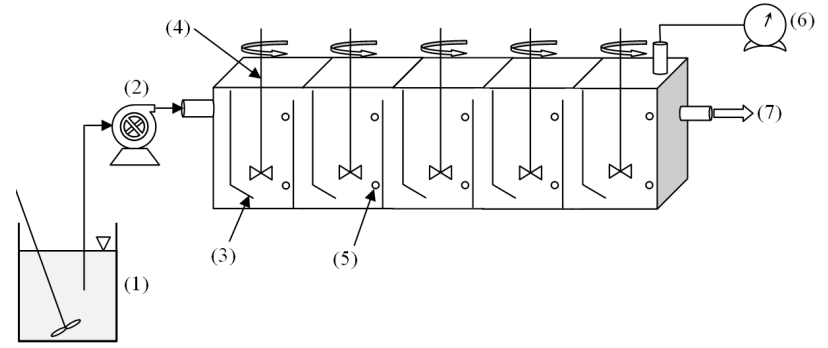

Figure 1. Schematic diagram of the anaerobic migrating blanket reactor (AMBR): (1) Feed tank, (2) Feed pump, (3) Baffle, (4) Mixer, (5) Sampling port, (6) Gas meter, and (7) Effluent.

The influent wastewater was introduced to the AMBR with an electrical pump (hose pump) and the trapped solids were discharged periodically from the sedimentation tank. The liquid and gas samples and also biological solids were extracted from each compartment via sampling ports. The sampling ports were installed at two heights (10 and $15 \mathrm{~cm}$ from floor). A mechanical mixer was employed for the sufficient contact between biomass and influent substrate. The mixers were attached with paddles with $1.5 \mathrm{~cm}$ in height and $5 \mathrm{~cm}$ in width in 12.5 and 2.5 minutes for idle and mixing time at $80 \mathrm{rpm}$, respectively. In order to separate the AMBR headspace of the outside compartment from the air, an effluent baffle was equipped and led to flow out of the AMBR via gravity without biogas losing from the headspace. The AMBR was operated at 37 $\pm 1^{\circ} \mathrm{C}$ by a thermostatically regulated recirculating hot water bath. The AMBR was operated at five OLRs $(0.5,1$, 2, 4, and $8 \mathrm{~g} \mathrm{COD/L.d)} \mathrm{and} \mathrm{equal} \mathrm{to} 1.25,2.5,5,10$, and $20 \mathrm{~g} / \mathrm{L}$ with HRT equal to $2.5 \mathrm{~d}$. A wet gasmeter (ELSTERAMCO, Germany) was applied for monitoring the overall biogas production.

Inoculum and medium composition

The anaerobic sludge was taken from the South Municipal Wastewater Treatment Plant (Tehran, Iran). In order to eliminate particulate materials, it was screened with sieve No. 16. The characteristics of anaerobic sludge including average $\mathrm{pH}$, soluble chemical oxygen demand (COD), total COD, total suspended solids, and volatile suspended solids concentrations were obtained to be $7.75 \pm 0.1,2.5 \pm$ $0.4 \mathrm{~g} / \mathrm{L}, 12.6 \pm 2.2 \mathrm{~g} / \mathrm{L}, 32.56 \pm 6.58 \mathrm{~g} / \mathrm{L}$, and $16.84 \pm 3.4$ $\mathrm{g} / \mathrm{L}$, respectively. The physically sludge pretreatment was done at $100^{\circ} \mathrm{C}$ for 30 minutes in order to selectively enrich spore-forming hydrogen producing microflora according to our previous work (25).

The sole carbon source used for hydrogen fermentation with the pretreated anaerobic sludge was glucose. As a function of influent COD, the inorganic nutrients $\left(\mathrm{KH}_{2} \mathrm{PO}_{4}: 10.00 \mathrm{mg} / \mathrm{g} \mathrm{COD}\right.$ and $\left.\mathrm{NH}_{4} \mathrm{Cl}: 76.45 \mathrm{mg} / \mathrm{g} \mathrm{COD}\right)$, trace elements as $\mathrm{mg} / \mathrm{g} \mathrm{COD}\left(\mathrm{FeCl}_{3}: 1.021, \mathrm{~K}_{2} \mathrm{HPO}_{4}: 25.32\right.$, $\mathrm{CaCl}_{2} \cdot 2 \mathrm{H}_{2} \mathrm{O}: 2.06, \mathrm{MnCl}_{2} \cdot 2 \mathrm{H}_{2} \mathrm{O}: 0.34, \mathrm{MgSO}_{4} \cdot 7 \mathrm{H}_{2} \mathrm{O}:$ 2.14, $\mathrm{NiSO}_{4} \cdot 6 \mathrm{H}_{2} \mathrm{O}: 0.0763, \mathrm{CoCl}_{2} \bullet 6 \mathrm{H}_{2} \mathrm{O}: 0.092, \mathrm{ZnSO}_{4}$ : $0.0592, \mathrm{H}_{3} \mathrm{BO}_{3}: 0.020, \mathrm{Na}_{2} \mathrm{MoO}_{4} \cdot 2 \mathrm{H}_{2} \mathrm{O}: 0.0822$, and
$\left.\mathrm{CuCl}_{2} \bullet 2 \mathrm{H}_{2} \mathrm{O}: 0.016\right)$, as well as yeast extract: $36 \mathrm{mg} / \mathrm{L}$ and peptone: $36 \mathrm{mg} / \mathrm{L}$ were added (26). In addition, to provide the initial $\mathrm{BC}, 1.87 \mathrm{~g} / \mathrm{L}$ of $\mathrm{NaHCO}_{3}\left(\mathrm{NaHCO}_{3} / \mathrm{COD}\right.$ ratio: $0.25)$ was added.

Data analysis

In the both influent and effluent wastewater, the solution $\mathrm{pH}$, oxidation-reduction potential (ORP), alkalinity, tCOD, and sCOD were measured using a glass body $\mathrm{pH}$ probe (CG 824 SCHOTT), multi parameter device (WA.2017 SD, Lutron Electronic Enterprise Co. LTD), and titration and colorimetric methods (27). Using GCFID, VFAs (acetate, propionate, lactate, and butyrate) were analyzed after liquid-liquid extraction and solvents (methanol, ethanol, and acetone) were measured using automatic headspace injections (28). The purity of biogas in respect of hydrogen was evaluated with a hydrogen analyzer (COSMOS-XP-3140 model, Japan).

\section{Results}

Biohydrogen production

The variations of biological hydrogen productions and volumetric hydrogen production rate (VHPR) in the AMBR are shown in Figure 2 for all OLRs studied. As shown in this figure, with increasing the OLR from 0.5 to $8 \mathrm{~g} \mathrm{COD} / \mathrm{L}$.d, the biogas $\left(\mathrm{H}_{2}\right)$ production and also VHPR improved. The daily hydrogen gas production enhanced from 0.41 to $4.47 \mathrm{~L} / \mathrm{d}$, when the OLRs increased from 0.5 to $8 \mathrm{~g} \mathrm{COD/L.d.} \mathrm{At} \mathrm{this} \mathrm{stage,} \mathrm{the} \mathrm{hydrogen} \mathrm{content} \mathrm{of}$ biogas declined from 48 to $37 \%$.

The steepness of the hydrogen yield in respect of OLR is shown in Figure 3. As the OLR increased from 0.5 to $8 \mathrm{~g}$ COD/L.d, the average hydrogen yield rate declined from $1.58 \pm 0.34$ to $0.97 \pm 0.45 \mathrm{~mol} \mathrm{H}_{2} / \mathrm{mol}$ glucose. Thus, the increase of OLR up to $8 \mathrm{~g}$ COD/L.d is negatively affected the hydrogen yield.

\section{COD removal efficiency}

Figure 4a presents the COD removal efficiency and the amount of removed COD as a function of the OLR during the AMBR operation. As seen in Figure $4 \mathrm{a}$, during the initial stages of the AMBR operation, the COD removal

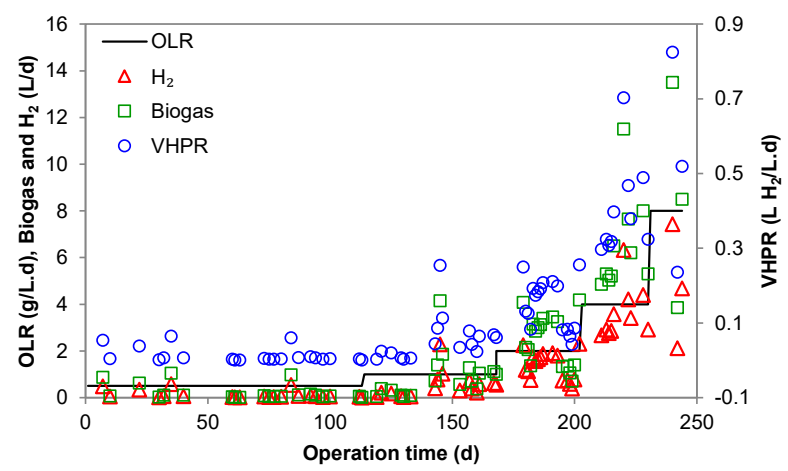

Figure 2. OLR dependent profile of hydrogen production by the AMBR 


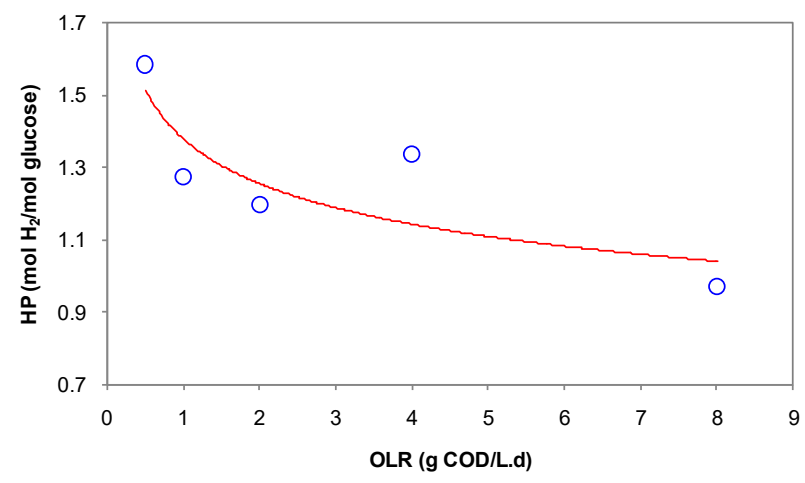

Figure 3. Hydrogen production yields as a function of the OLR.
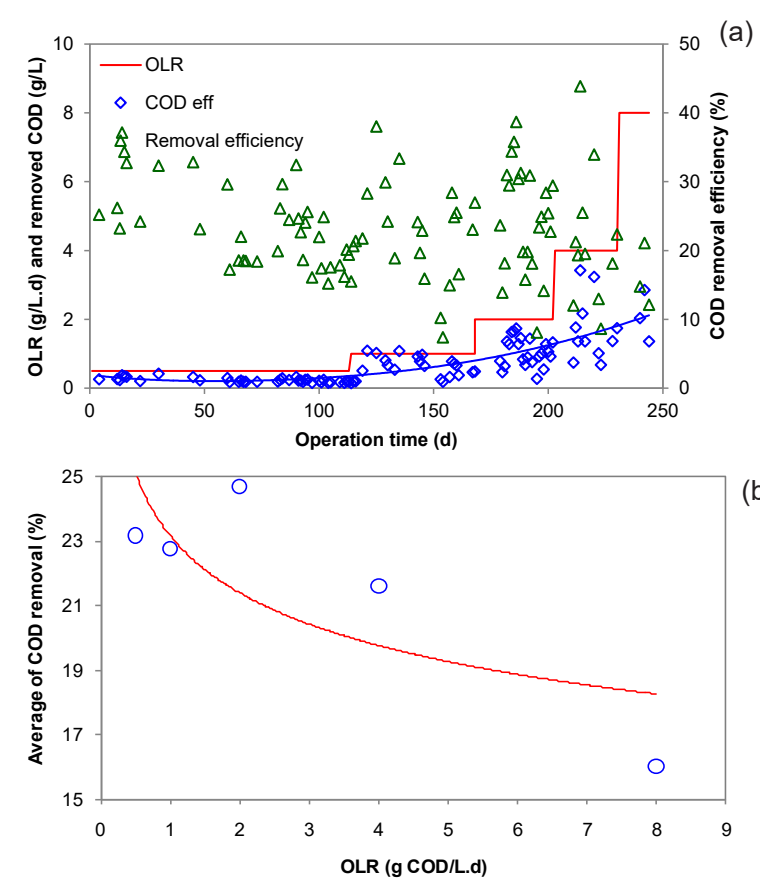

Figure 4. The variation of removed substrate and COD removal efficiency during the AMBR operation (a) and the average of COD removal as a function of the OLR (b).

efficiency of 9\% (OLR $0.5 \mathrm{~g}$ COD/L.d) was observed. Furthermore, at the end of the cycle period, the AMBR operation with an OLR of $0.5 \mathrm{~g} \mathrm{COD} / \mathrm{L} . \mathrm{d}$, registered a COD removal efficiency of $28 \%$. Afterwards, with increasing the OLR ( 1 g COD/L.d), first, the COD removal efficiency promptly increased to $40 \%$, but then due to dilution effect, reduced to $20 \%$.

The removal of COD increased greatly with increasing the OLR of AMBR fermentation (Figure 4a). The higher removal of COD is related to the higher influent loading.

Soluble End Products

As previously mentioned, the distribution and fraction of microbial soluble metabolites including VFAs and alcohols were used as monitoring indicators of anaerobic hydrogen production system (29). Figure 5 illustrates the results of soluble end products (SEPs) production during
AMBR operation as a function of the OLR. As obvious in Figure 5, the SEPs production and their characteristics were significantly related to the applied OLR.

\section{Alkalinity, $\mathrm{pH}$, and ORP of the effluent}

The variations of the effluent alkalinity, $\mathrm{pH}$, and ORP during the AMBR operation are shown in Figure 6. Before reaching stable AMBR performance, fluctuation was observed in the effluent solution $\mathrm{pH}$. As shown in Figure 6 , $\mathrm{pH}$ drop showed a distinct trend towards acidification.

\section{Discussion}

The amount of hydrogen production per volume of AMBR should be taken into account as an indicator for the comparison of the obtained results. In this study, as seen in Figure 2, at OLR of $0.5 \mathrm{~g} \mathrm{COD/L.d,} \mathrm{the} \mathrm{average}$ of VHPR was $0.04 \pm 0.02 \mathrm{~L} \mathrm{H}_{2} / \mathrm{L} . \mathrm{d}$ and improved to 0.53 $\pm 0.29 \mathrm{~L} \mathrm{H}_{2} / \mathrm{L}$.d by applying $8 \mathrm{~g} \mathrm{COD} / \mathrm{L}$.d. In a study performed by Guo et al, the operation of the expanded granular sludge bed (EGSB) reactor showed that the highest HPR of $0.71 \mathrm{~L} \mathrm{H}_{2} / \mathrm{L}$.d was achieved at OLR of $120 \mathrm{~g} \mathrm{COD} / \mathrm{L} . \mathrm{d}$ (21). Fuess et al investigated biohydrogen production using continuous acidogenic packed-bed reactor and found that the VHPR was fluctuated from 0.4 to $0.8 \mathrm{~L} \mathrm{H}_{2} / \mathrm{L} . \mathrm{d}$ (30). The calculated VHPR in this study is slightly lower than that obtained in the previous study and could be attributed to the reactor configuration, initial

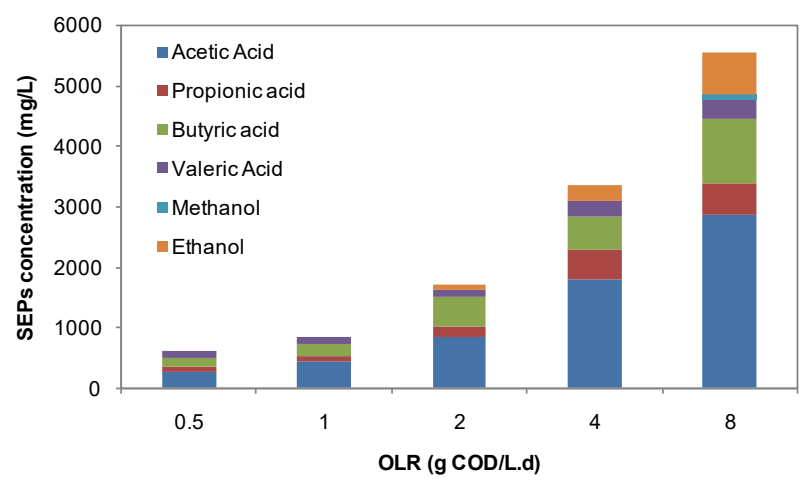

Figure 5. The influence of OLR on the SEPs distribution during the AMBR operation..

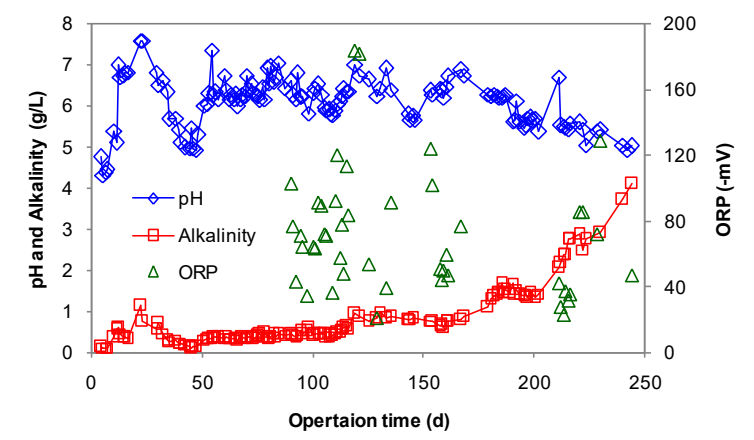

Figure 6. The variation of $\mathrm{pH}$, alkalinity, and ORP in the AMBR operation. 
inoculum, OLR, and HRT of the reactor, as well as the influent substrate concentration.

The increase of OLR up to $8 \mathrm{~g}$ COD/L.d has negative effect on the biological hydrogen yield. This situation may be due to VFAs accumulation at higher OLRs, in addition, the supersaturation of hydrogen in liquid phase may be related to the lower biogas production and relieving inhibition due to hydrogen (31).

In a study by Van Ginkel et al, the average hydrogen yield increased from 1.8 to $2.6 \mathrm{~mol} \mathrm{H}_{2} / \mathrm{mol}$ glucose as the glucose concentration reduced from 10 to $2.5 \mathrm{~g} \mathrm{COD} / \mathrm{L}$ (31). Nasr et al used an up-flow anaerobic staged reactor for biohydrogen production from starch wastewater and demonstrated that as OLR increased from 18 to $108 \mathrm{~g}$ COD/L.d, the hydrogen yield decreased (32). Kongjan et al reported that with increasing hydrogen production, OLR increased, but the increase of OLR to $120 \mathrm{~g} / \mathrm{L}$, resulted in light and sharp decrease in the hydrogen production rate and yield, respectively (33). A similar trend was reported by Buitrón et al (34). In case of other studied OLR, the same trend was observed. Overall, the variation of COD removal ranged between 9 and $42 \%$ in the OLR studied. Searmsirimongkol et al studied the hydrogen production from alcohol distillery wastewater using an ASBR and reported that the COD removal efficiency was 15\%-28\% by applying the OLR of $15-37.5 \mathrm{~kg} / \mathrm{m}^{3} . \mathrm{d}(35)$.

The average COD removal efficiency in the studied OLR is illustrated in Figure $4 \mathrm{~b}$. As shown in Figure $4 \mathrm{~b}$, the COD removal efficiency was declined with increasing the OLR, which is consistent with the results of other studies (36-38). As previously stated, the biological hydrogen production during anaerobic degradation of organic matters is related to the COD removal (39). In biological hydrogen production process, the COD removal occurred via the release of cytogenesis and biogas (mainly $\mathrm{CO}_{2}$ and $\mathrm{H}_{2}$ ), while a significant fraction of COD was converted to SEPs and remained in the system (40). This manner leads to the lower COD removal efficiency during acidogenic phase compared to methanogenic phase. Due to conversion nature of biohydrogen production process (conversion of influent substrate to VFAs and solvents), the COD removal efficiency is not a good indicator for the evaluation of the process efficiency.

The concentration of both VFAs and solvents kept increasing with OLR. The dominant SEPs during AMBR operation were acetic and butyric acids in the all of OLRs. The high acetic and butyrate concentrations showed that the biological reaction was followed by acetic/butyrate fermentation. At this situation, Clostridium sp. are registries as dominant microorganisms in the anaerobic reactor due to their ability to ferment acetic/butyrate $(36,41,42)$.

The results demonstrated that the sum of VFAs concentrations distinctly affects the AMBR performance, in respect of both biological hydrogen yield and COD removal. The VFA production is influenced by the metabolic pathway used by bacteria and the rate of mass transfer. In addition, the accumulation of the undissociated VFA forms leads to the shift of hydrogen production to solvent production (34). Methanol and ethanol were detected for higher studied OLRs with significantly lower concentrations than VFAs. The lower solvents production indicated that the fermentations occurred in the AMBR were acidogenic rather than solventogenic, which is consistent with the results of the pervious study (31). The hydrogen fermentation changed to a solvent forming reaction at higher OLRs presumably is related to a decrease in the glucose flux through glycolysis by tying up the CoA and PO4 pools by the uptake of acids (43). The acetone was not detected during the AMBR operation.

Previous studies reported that for monitoring the anaerobic hydrogen production process, the solution $\mathrm{pH}$, alkalinity, and ORP are the important factors. Variation of the above-mentioned parameters is affected not only by the anaerobic hydrogen production ability, but also by the microbial community and fermentation types (40).

During the AMBR operation, acid production during biological process lead to VFAs accumulation in the AMBR and a gradual reduction in BC (total alkalinity), which resulted in a simultaneous drop in the solution $\mathrm{pH}$. The $\mathrm{pH}$ variation during stabilization phase of AMBR operation was $6.31 \pm 0.29,6.39 \pm 0.41,5.89 \pm 0.34,5.55$ \pm 0.4 , and $5 \pm 0.1$ at different operating OLR. The $\mathrm{pH}$ variation in a narrow range showed a stable system. The previous research reported that the effluent $\mathrm{pH}$ ranged between 4.5 and $7.5(37,38,44,45)$. Clostridium sp. are usually the dominant producers of hydrogen in acetate/ butyrate fermentation with the optimal $\mathrm{pH}$ ranging between 5 and $6(31,46,47)$.

In the case of ORP values, the ORP decreased from $-47 \mathrm{mV}$ at the beginning of the AMBR operation to $-130 \mathrm{mV}$ at the end of the operation period. As seen in Figure 6, in the AMBR process, the values of ORP were mainly attributed to $\mathrm{pH}$. In the previous study, the ORP value in the effluent of hydrogen production processes was reported to be -5 to $-600 \mathrm{mV}(29,40,44)$, which is consistent with the results of the present study. In contrast, Venkata Mohan et al studied the application of biofilm configured reactor for the biohydrogen production and reported that the effluent ORP ranged 82 to $145 \mathrm{mV}$ (37).

For understanding the buffering activity of the AMBR, the alkalinity of the effluent was monitored and shown in Figure 6. The ascending trend of the effluent alkalinity was observed during the AMBR operation. As previously stated, due to the balance of $\mathrm{pH}$ level $\left(\left[\mathrm{CO}_{2}\right]\right.$ and $\left.\left[\mathrm{HCO}_{3}^{-}\right]\right)$ within the reactor, the effluent alkalinity plays a critical role in the inhibition of VFAs accumulation and leading to substrate removal and biological hydrogen production $(38,40)$.

Artificial neural network (ANN)

In order to generate neural network model, the MATLAB 
software (The Mathworks Inc., 2012) was used. To ensure more efficient training of the ANN, the targets and inputs were preprocessed by normalizing them (ranging 0 to 1 ) using 'PREMNMX' function. For mapping the input to hidden layer, the sigmoid transfer function, 'TANSIG' (hyperbolic tangent), was selected and also for mapping the hidden layer to output layer, 'PURELIN' (pure linear transfer function) was chosen. To construct the ANN model, the inputs and their corresponding outputs data were randomly segregated into three data sets including $70 \%$ for training (new model development), 15\% for validation, and $15 \%$ for model reliability testing. In this study, the multilayer perceptron with back-propagation algorithm was trained in order to report the ability of feed-forward architecture of the ANN.

In this study, the optimum number of neurons $(\mathrm{N})$ in the hidden layer was determined according to a trial and error approach. Therefore, different numbers of neurons in the range of 1-15 were tested in the hidden layer and the optimum hidden layer size was determined according to the minimum value of MSE and $\mathrm{R}^{2}$ of the prediction data set. As seen in Figure 7, with increasing the number of neurons in the hidden layer, the value of MSE decreased promptly, and then increased.

As shown in Figure 7, three-layer feed forward back propagation neural network including 3:5:1, 3:9:1, and 3:6:1 were respectively used for modeling the effluent COD concentration hydrogen production.

Figure 8 shows a comparison between experimental values
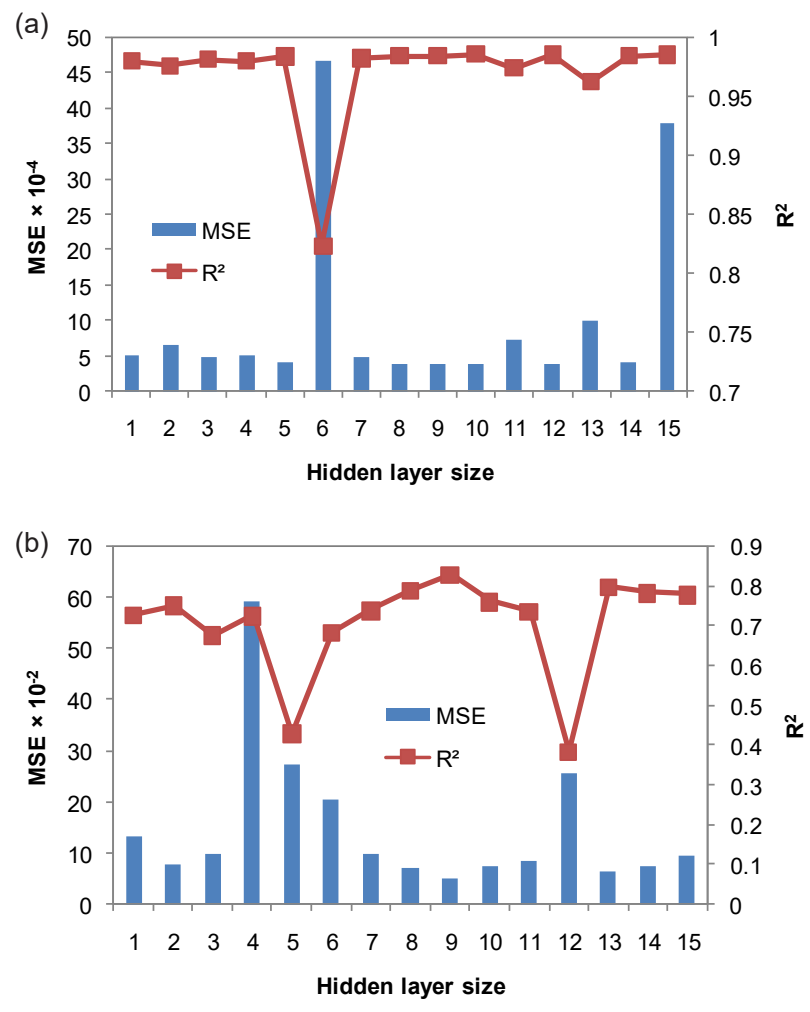

Figure 7. The variation of MSE and R2 as a function of hidden layer size: (a) effluent SCOD and (b) hydrogen production. of sCOD and hydrogen production and the predicted ANN values. As shown in this figure, the value of $R^{2}$ for the ANN model was found to be up to 0.92 .

The ANN was an excellent model because of the lowest error and the highest coefficient values. The obtained results indicated that the simulation model based on the ANN is practical.

\section{Conclusion}

According to the obtained results, the following point can be concluded.

- The AMBR could simultaneously be used for the wastewater treatment and hydrogen production.

- With increasing the OLR value from 0.5 to $8 \mathrm{~g}$ COD/L.d, the hydrogen production and also VHPR improved.

- Hydrogen yields decreased from 1.58 to $0.97 \mathrm{~mol}$ $\mathrm{H}_{2} /$ mol glucose as the OLR increased from 0.5 to 8 g COD/L.d

- The concentration of both VFAs and solvents kept increasing with OLR. During the AMBR operation, the dominant SEPs during the AMBR operation were acetic and butyric acids in the all OLRs.

- The ANN model was well fitted to the experimental obtained data from the AMBR, and was able to simulate the COD removal and hydrogen production.

\section{Acknowledgments}

This study was supported by the Isfahan University of
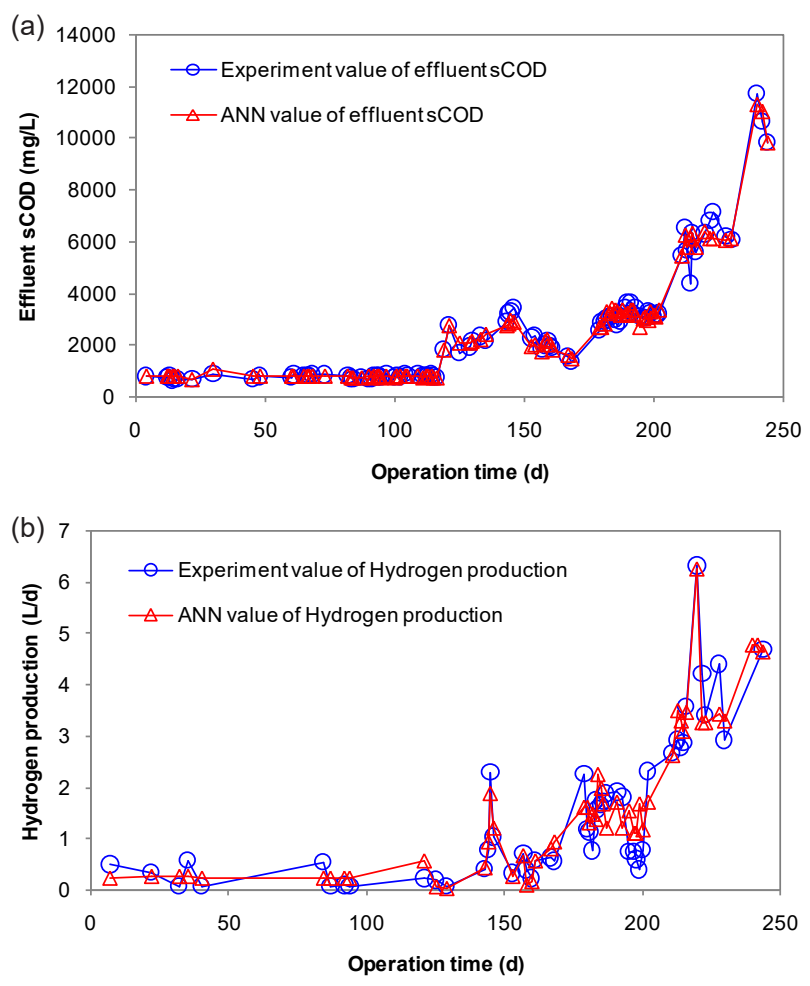

Figure 8. The comparison between experimental and ANN values in the AMBR. 
Medical Sciences (grant No. 193043).

\section{Ethical issues}

The authors certify that this manuscript is the original work of the authors, and all data collected during the study are presented in this manuscript, and no data from the study has been or will be published separately elsewhere.

\section{Competing interests}

The authors declare that they have no conflict of interests.

\section{Authors' contributions}

Mohammad Mehdi Amin supervised the study, Mohammad Ghasemian and Ali Fatehizadeh was the main investigators, and Mohammad Ghasemian, Ensiyeh Taheri, and Ali Fatehizadeh drafted the manuscript. All authors read and approved the final manuscript.

\section{References}

1. Christopher K, Dimitrios R. A review on exergy comparison of hydrogen production methods from renewable energy sources. Energy Environ Sci 2012; 5(5): 6640-51. doi: 10.1039/C2EE01098D.

2. Amin MM, Bina B, Taheri E, Zare MR, Ghasemian M, Van Ginkel SW, et al. Metabolism and kinetic study of bioH2 production by anaerobic sludge under different acid pretreatments. Process Biochem 2017; 61: 24-9. doi: 10.1016/j.procbio.2017.06.015.

3. Lipman T. An Overview of Hydrogen Production and Storage Systems with Renewable Hydrogen Case Studies. Montpelier: Clean Energy States Alliance; 2011.

4. Brentner LB, Peccia J, Zimmerman JB. Challenges in developing biohydrogen as a sustainable energy source: implications for a research agenda. Environ Sci Technol 2010; 44(7): 2243-54. doi: 10.1021/es9030613.

5. Hallenbeck PC, Ghosh D. Advances in fermentative biohydrogen production: the way forward? Trends Biotechnol 2009; 27(5): 287-97. doi: 10.1016/j. tibtech.2009.02.004.

6. Levin DB, Pitt L, Love M. Biohydrogen production: prospects and limitations to practical application. Int J Hydrogen Energy 2004; 29(2): 173-85. doi: 10.1016/S03603199(03)00094-6.

7. Okamoto M, Miyahara T, Mizuno O, Noike T. Biological hydrogen potential of materials characteristic of the organic fraction of municipal solid wastes. Water Sci Technol 2000; 41(3): 25-32. doi: 10.2166/wst.2000.0052.

8. Amin MM, Bina B, Taheri E, Fatehizadeh A, Ghasemian M. Stoichiometry evaluation of biohydrogen production from various carbohydrates. Environ Sci Pollut Res Int 2016; 23: 20915-21. doi: 10.1007/s11356-016-7244-6.

9. Taheri E, Amin MM, Pourzamani H, Fatehizadeh A, Ghasemian M, Bina B. Comparison of acetate-butyrate and acetate-ethanol metabolic pathway in biohydrogen production. J Med Signals Sens 2018; 8(2): 101-7.

10. Amin MM, Taheri E, Bina B, van Ginkel SW, Ghasemian M, Puad NI, et al. Electron flow of biological $\mathrm{H} 2$ production by sludge under simple thermal treatment: Kinetic study. J Environ Manage 2019; 250: 109461. doi: 10.1016/j. jenvman.2019.109461.

11. Hafez H, Nakhla G, El Naggar MH, Elbeshbishy E, Baghchehsaraee B. Effect of organic loading on a novel hydrogen bioreactor. Int J Hydrogen Energy 2010; 35(1): 81-92. doi: 10.1016/j.ijhydene.2009.10.051.

12. Devi MP, Mohan SV, Mohanakrishna G, Sarma PN. Regulatory influence of $\mathrm{CO} 2$ supplementation on fermentative hydrogen production process. Int $\mathrm{J}$ Hydrogen Energy 2010; 35(19): 10701-9. doi: 10.1016/j. ijhydene.2010.03.024

13. Zhu H, Parker W, Basnar R, Proracki A, Falletta P, Béland $M$, et al. Buffer requirements for enhanced hydrogen production in acidogenic digestion of food wastes. Bioresour Technol 2009; 100(21): 5097-102. doi: 10.1016/j. biortech.2009.02.066

14. Chandra R, Venkata Mohan S. Microalgal community and their growth conditions influence biohydrogen production during integration of dark-fermentation and photofermentation processes. Int J Hydrogen Energy 2011; 36(19): 12211-9. doi: 10.1016/j.ijhydene.2011.07.007.

15. Lee DH. Efficiency and economic benefit of darkfermentative biohydrogen production in Asian circular economies: Evaluation using soft-link methodology with data envelopment analysis (DEA) and computable general equilibrium model (CGE). Int J Hydrogen Energy 2019; (In Press). doi: 1016/j.ijhydene.2019.08.250.

16. Bina B, Amin MM, Pourzamani H, Fatehizadeh A, Ghasemian M, Mahdavi M, et al. Biohydrogen production from alkaline wastewater: the stoichiometric reactions, modeling, and electron equivalent. MethodsX 2019; 6: 1496-505. doi: 10.1016/j.mex.2019.06.013.

17. Taheri E, Amin MM, Fatehizadeh A, Pourzamani H, Bina B, Spanjers H. Biohydrogen production under hyper salinity stress by an anaerobic sequencing batch reactor with mixed culture. J Environ Health Sci Eng 2018; 16(2): 159-70. doi: 10.1007/s40201-018-0304-8.

18. Kuscu OS, Sponza DT. Performance of p-nitrophenol (pNP) fed sequential anaerobic migrating blanket reactor (AMBR)/aerobic completely stirred tank reactor (CSTR) system under increasing organic loading conditions. Enzyme Microb Technol 2007; 40(5): 1026-34. doi: 10.1016/j.enzmictec.2006.08.001

19. Ebrahimi A, Hashemi H, Eslami H, Fallahzadeh RA, Khosravi R, Askari R, et al. Kinetics of biogas production and chemical oxygen demand removal from compost leachate in an anaerobic migrating blanket reactor. J Environ Manage 2018; 206: 707-14. doi: 10.1016/j. jenvman.2017.10.038

20. Chen H, Kim AS. Prediction of permeate flux decline in crossflow membrane filtration of colloidal suspension: a radial basis function neural network approach. Desalination 2006; 192(1-3): 415-28. doi: 10.1016/j.desal.2005.07.045.

21. Guo WQ, Ren NQ, Chen ZB, Liu BF, Wang XJ, Xiang WS, et al. Simultaneous biohydrogen production and starch wastewater treatment in an acidogenic expanded granular sludge bed reactor by mixed culture for long-term operation. Int J Hydrogen Energy 2008; 33(24): 7397-404. doi: $\quad 10.1016 /$ j.ijhydene.2008.09.039.

22. Sadrzadeh M, Mohammadi T, Ivakpour J, Kasiri N. Neural network modeling of $\mathrm{Pb} 2+$ removal from wastewater using electrodialysis. Chem Eng Process 2009; 48(8): 1371-81. 
doi: 10.1016/j.cep.2009.07.001.

23. Giri AK, Patel RK, Mahapatra SS. Artificial neural network (ANN) approach for modelling of arsenic (III) biosorption from aqueous solution by living cells of Bacillus cereus biomass. Chem Eng J 2011; 178: 15-25. doi: 10.1016/j. cej.2011.09.111.

24. Özdemir U, Özbay B, Veli S, Zor S. Modeling adsorption of sodium dodecyl benzene sulfonate (SDBS) onto polyaniline (PANI) by using multi linear regression and artificial neural networks. Chem Eng J 2011; 178: 183-90. doi: 10.1016/j. cej.2011.10.046.

25. Fatehizadeh A, Amin MM, Bina B, Zare MR, Ghasemian $\mathrm{M}$, Taheri E. Biohydrogen production as clean fuel from physically pretreated mixed culture. Adv Biomed Res 2018; 7: 80. doi: 10.4103/2277-9175.233030.

26. Amin MM, Zilles JL, Greiner J, Charbonneau S, Raskin L, Morgenroth E. Influence of the antibiotic erythromycin on anaerobic treatment of a pharmaceutical wastewater. Environ Sci Technol 2006; 40(12): 3971-7. doi: 10.1021/ es060428j.

27. Baird R, Eaton AD, Rice EW, Bridgewater L, American Public Health Association, American Water Works Association, et al. Standard methods for the examination of water and wastewater. 23rd ed. Washington, DC: American Public Health Association; 2017.

28. Adorno MA, Hirasawa JS, Varesche MB. Development and validation of two methods to quantify volatile acids (C2C6) by GC/FID: headspace (automatic and manual) and liquid-liquid extraction (LLE). Am J Anal Chem 2014; 5(7): 406-14. doi: 10.4236/ajac.2014.57049.

29. Chang FY, Lin CY. Biohydrogen production using an upflow anaerobic sludge blanket reactor. Int J Hydrogen Energy 2004; 29(1): 33-9. doi: 10.1016/S0360-3199(03)00082-X.

30. Fuess LT, Mazine Kiyuna LS, Garcia ML, Zaiat M. Operational strategies for long-term biohydrogen production from sugarcane stillage in a continuous acidogenic packed-bed reactor. Int J Hydrogen Energy 2016; 41(19): 8132-45. doi: 10.1016/j.ijhydene.2015.10.143.

31. Van Ginkel SW, Logan B. Increased biological hydrogen production with reduced organic loading. Water Res 2005; 39(16): 3819-26. doi: 10.1016/j.watres.2005.07.021.

32. Nasr M, Tawfik A, Ookawara S, Suzuki M. Biological hydrogen production from starch wastewater using a novel up-flow anaerobic staged reactor. BioRecourses 2013; 8(4): 4951-68. doi: 10.15376/biores.8.4.4951-4968.

33. Kongjan P, Inchan S, Chanthong S, Jariyaboon R, Reungsang A, O-Thong S. Hydrogen production from xylose by moderate thermophilic mixed cultures using granules and biofilm up-flow anaerobic reactors. Int J Hydrogen Energy 2019; 44(6): 3317-24. doi: 10.1016/j.ijhydene.2018.09.066.

34. Buitrón G, Muñoz-Páez KM, Hernández-Mendoza CE. Biohydrogen production using a granular sludge membrane bioreactor. Fuel 2019; 241: 954-61. doi: 10.1016/j. fuel.2018.12.104.

35. Searmsirimongkol P, Rangsunvigit P, Leethochawalit M, Chavadej S. Hydrogen production from alcohol distillery wastewater containing high potassium and sulfate using an anaerobic sequencing batch reactor. Int J Hydrogen Energy 2011;36(20): 12810-21. doi: 10.1016/j.ijhydene.2011.07.080.

36. Vijaya Bhaskar Y, Venkata Mohan S, Sarma PN. Effect of substrate loading rate of chemical wastewater on fermentative biohydrogen production in biofilm configured sequencing batch reactor. Bioresour Technol 2008; 99(15): 6941-8. doi: 10.1016/j.biortech.2008.01.029.

37. Venkata Mohan S, Vijaya Bhaskar Y, Sarma PN. Biohydrogen production from chemical wastewater treatment in biofilm configured reactor operated in periodic discontinuous batch mode by selectively enriched anaerobic mixed consortia. Water Res 2007; 41(12): 2652-64. doi: 10.1016/j. watres.2007.02.015.

38. Venkata Mohan S, Lalit Babu V, Sarma PN. Anaerobic biohydrogen production from dairy wastewater treatment in sequencing batch reactor (AnSBR): effect of organic loading rate. Enzyme Microb Technol 2007; 41(4): 506-15. doi: 10.1016/j.enzmictec.2007.04.007.

39. Ren N, Li J, Li B, Wang Y, Liu S. Biohydrogen production from molasses by anaerobic fermentation with a pilot-scale bioreactor system. Int J Hydrogen Energy 2006; 31(15): 2147-57. doi: 10.1016/j.ijhydene.2006.02.011.

40. Li J, Li B, Zhu G, Ren N, Bo L, He J. Hydrogen production from diluted molasses by anaerobic hydrogen producing bacteria in an anaerobic baffled reactor (ABR). Int J Hydrogen Energy 2007; 32(15): 3274-83. doi: 10.1016/j. ijhydene.2007.04.023.

41. Chen CC, Lin CY, Chang JS. Kinetics of hydrogen production with continuous anaerobic cultures utilizing sucrose as the limiting substrate. Appl Microbiol Biotechnol 2001; 57(1): 56-64. doi: 10.1007/s002530100747.

42. Jones DT, Woods DR. Acetone-butanol fermentation revisited. Microbiol Rev 1986; 50(4): 484-524.

43. Gottwald M, Gottschalk G. The internal pH of Clostridium acetobutylicum and its effect on the shift from acid to solvent formation. Arch Microbiol 1985; 143(1): 42-6. doi: 10.1007/bf00414766.

44. Lin CY, Wu SY, Lin PJ, Chang JS, Hung CH, Lee KS, et al. A pilot-scale high-rate biohydrogen production system with mixed microflora. Int J Hydrogen Energy 2011; 36(14): 8758-64. doi: 10.1016/j.ijhydene.2010.07.115.

45. Venkata Mohan S, Mohanakrishna G, Ramanaiah SV, Sarma PN. Simultaneous biohydrogen production and wastewater treatment in biofilm configured anaerobic periodic discontinuous batch reactor using distillery wastewater. Int J Hydrogen Energy 2008; 33(2): 550-8. doi: 10.1016/j.ijhydene.2007.10.013.

46. Lee HS, Krajmalinik-Brown R, Zhang H, Rittmann BE. An electron-flow model can predict complex redox reactions in mixed-culture fermentative bioH2: microbial ecology evidence. Biotechnol Bioeng 2009; 104(4): 687-97. doi: 10.1002/bit.22442.

47. Fang HH, Zhang T, Li C. Characterization of Fe-hydrogenase genes diversity and hydrogen-producing population in an acidophilic sludge. J Biotechnol 2006; 126(3): 357-64. doi: 10.1016/j.jbiotec.2006.04.023. 